\title{
THERMO-HYDRAULIC PERFORMANCE ANALYSIS OF PARABOLIC CONCENTRATING SOLAR WATER HEATER
}

\author{
Amit Kumar Bhakta ${ }^{1, *}$, S N Singh ${ }^{1}$
}

\begin{abstract}
This paper concerns the thermo-hydraulic performance analysis of a PCSWH (parabolic concentrating solar water heater) with placing the PTT (perforated twisted tape) in the absorber tube. The experiments are performed using water as testing fluid. In this analysis, the mass flow rate changes from $0.0326 \mathrm{~kg} / \mathrm{s}$ to $0.0667 \mathrm{~kg} / \mathrm{s}$ and Reynolds number ranges from 2100 to 4250 respectively. The analysis is based on the effect of porosity of the PTT and mass flow rate over the pressure drop and heat transfer enhancement during the flow into the absorber tube of the PCSWH. At last to guess the increment in pressure drop and enhancement of heat transfer the empirical correlations for friction factor and the Nusselt number have been formulated considering the turbulent effect caused by PTT inside the absorber tube. The major observations of this analysis are that PTT enhances the pressure drop and heat transfer and also both enhances with increasing porosity of the PTT.
\end{abstract}

Keywords: Solar Water Heater, Perforated Twisted Tape, Thermo-Hydraulic Performance, Pressure Drop, Heat Transfer

\section{INTRODUCTION}

Solar energy is a most important source of renewable energy as it is pollution free and no fuel consumption required. Only the collecting device required with modern improved technology. The demand for energy is increasing with the progress of society and civilization of the forthcoming years. A concentrating solar collector is the most eminent and efficient technique to collect the solar energy due to its higher concentration ratio. A parabolic concentrating solar water heater is used for power generation and industrial water heating purposes. Lately, many research works are performed to improve the performance. The perforated twisted tape is one of passive technique to augment the heat transfer in the absorber tube. This is used Hong and Bergles [1] performed the thermo-hydraulic study of a tube with and without twisted tape inserts. Their result viewed that friction factor and Nusselt number both enhances for the tube with twisted tape inserts. Huang et al. [2] used a transparent absorber instead of a metal absorber tube and they observed that the thermal performance enhances for using black working fluid. Heiti and Thodos [3] studied the performances of the PTC with and without coated receiver tube. Hamad [4] examined the impact of variable mass flow rate over the thermal performance. Mullick and Nanda [5] examined the heat loss analysis numerically and experimentally. Manglik and Bergles [6] studied swirl flow parameters and developed correlations for pressure loss and heat transfer of an isothermal tube. Twisted tape improved heat transfer and enhances pressure drop. Kothdiwala et al. [7] studied the influence of the change of angular inclination on the collector performance. Agarwal and Raja Rao [8] found that Nussenlt number enhances with twisted tape inserts and same effect for friction factor. Eskin [9] experimentally reported the temperature profile of the glass envelope and receiver surface along the length of the receiver tube. Chang et al. [10] examined the thermo-hydraulic performance by using broken twisted tape in a tube and developed correlations for the results of enhancement in heat transfer and pressure drop. Arasu and Sornakumar [11] evaluated the collector thermal efficiency as per ASHRAE 93 (1986) Standard). Fadar et al. [12] studied the heat energy stored in the tank. Padilla et al. [13] developed correlations for thermal loss and collector efficiency. Kumaresan [14] performed the experimental study (charging efficiency, overall efficiency) of a parabolic trough collector. Their results showed that the above efficiencies are reached a peak value at noon. Jafar and Sivaraman [15] conducted the thermo-hydraulic study of an absorber tube of the parabolic trough collector. They used twisted tape and their results showed that pressure drop and Nusselt number simultaneously

This paper was recommended for publication in revised form by Regional Editor Erman Aslan

1 Department of Mechanical Engineering, IIT (ISM) Dhanbad, India

*E-mail address: bhakta_amit_kumar80@yahoo.co.in, snsingh.631@yahoo.com

Orcid id: 0000-0002-4066-160X; 0000-0001-7300-4182

Manuscript Received 24 September 2018, Accepted 22 January 2019 
augmented with low twist ratio. Ghomrassi et al. [16] numerically studied the influence of variation of receiver diameter on the thermal performance of a parabolic trough concentrator. Roy et al. [17] experimentally presents the effects of variable silver/water nano-fluid concentrations on the thermal performance of a flat solar plate collector. Bhakta et al. [18] studied the thermal performance of a CPCSWH for the two constant mass flow rates. Hussein et al. [19] found that nanofluid significantly augments the performance of direct absorption solar collector. Soudani et al. [20] examined the effects of mass flow rate, length of the absorber tube and glass cover on the thermal performance of the PTC. Yildirim and Ozdil [21] studied the performance of a solar air heater with the roughened absorber. Tokgoz et al. [22] numerically studied the heat transfer rate increment in a corrugated duct considering A12O3/water nanofluid as heat transfer fluid. Bhakta et al. [23] experimentally investigated the performance parameters of a CPC fitted with nailed twisted tape in an absorber tube.

After survey of above stated literatures, it is clear that the majority of the authors have studied the thermal performance of the PCSWH with plain receiver tube. Only Jafar and Sivaraman [15] investigated the thermohydraulic performance of the PCSWH fitted with nail and simple twisted tapes in a receiver tube. No research work observed in the parabolic trough collector with placing the perforated twisted tape (PTT) in the receiver tube. So, at present the investigation has focused to examine the thermo-hydraulic performance of a PCSWH with the PTT insert in the absorber tube.

\section{EXPERIMENTAL SETUP DESCRIPTION AND METHOD OF EXPERIMENT}

The photograph of PCSWH and photograph of the PTT have been shown in Figure 1 and Figure 2 respectively. The specifications of the PCSWH and PTT have been shown in Table 1. The PCSWH is equipped with a parabolic trough concentrator (PTC), a concentric glass-covered absorber tube, a pump and a storage tank. The PTC made of Acrylic mirror. The black nickel coated copper tube is used as absorber. The absorber tube is fitted along focal line of the PTC. The hydraulic hose pipes are used to connect between storage tank and absorber tube. Thus, a close loop formed and during the experimental work water circulates into this loop.

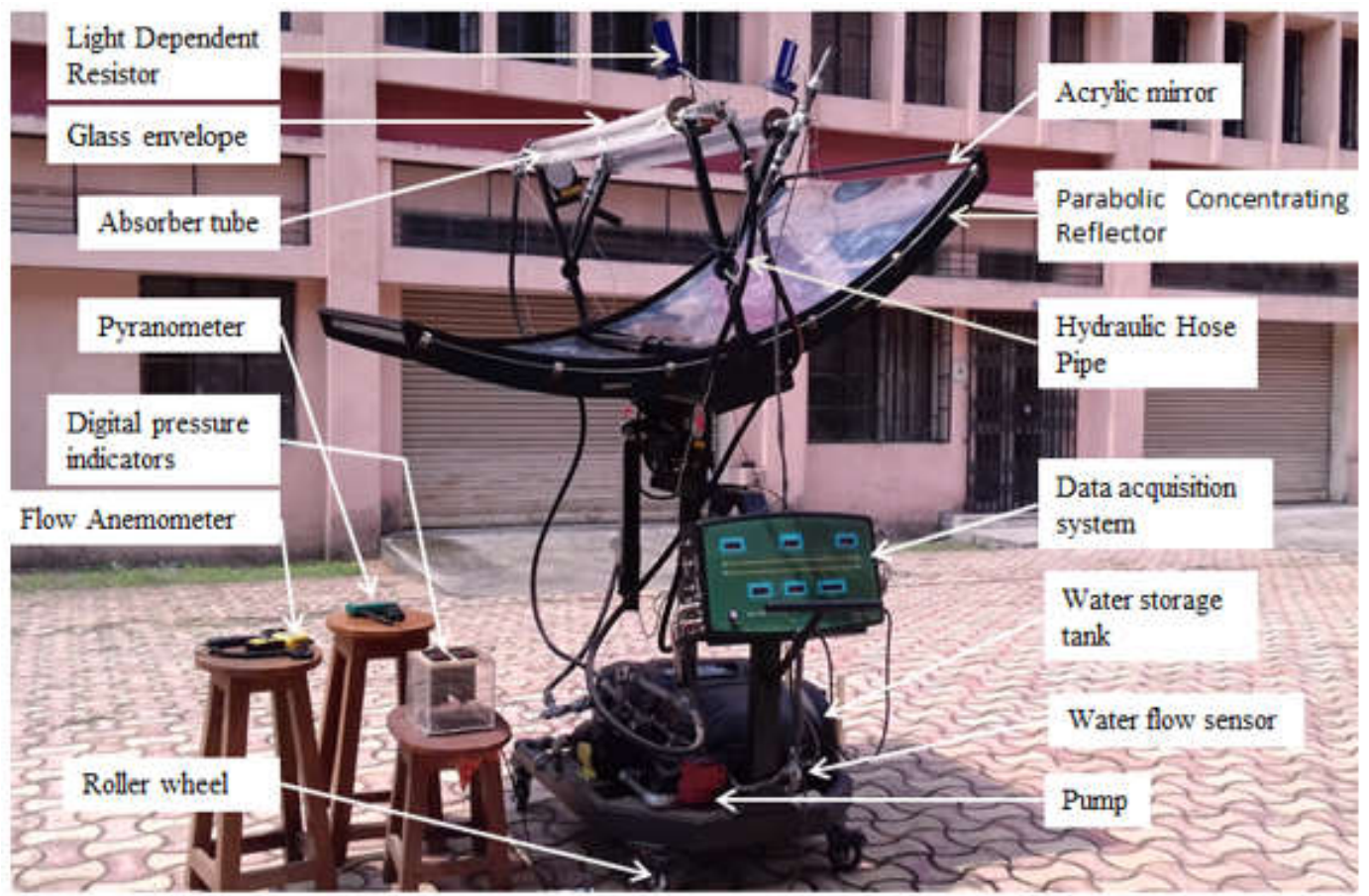

Figure1. Photograph of PCSWH 


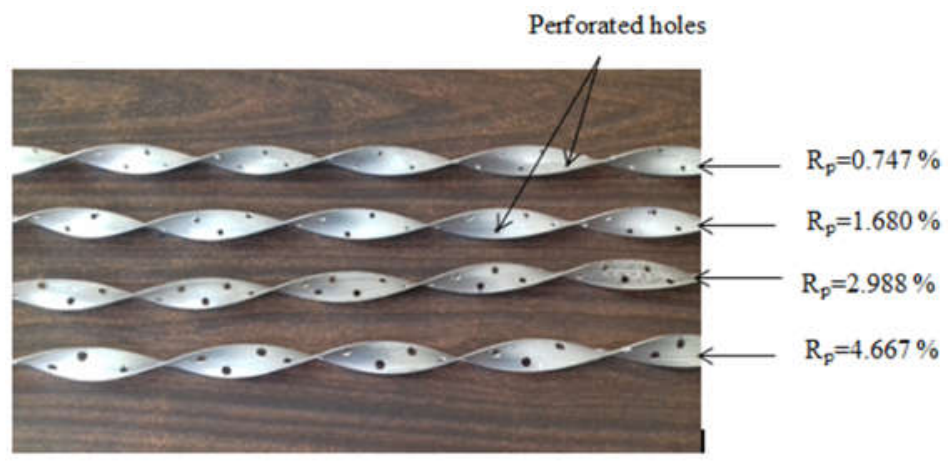

Figure 2. Photograph of PTT

Table 1. Specification of the geometrical characteristics of the PCSWH and PTT

\begin{tabular}{|c|c|c|}
\hline Sl. No. & Nomenclature & Specifications \\
\hline 1 & Concentrator aperture area $\left(\mathrm{A}_{\mathrm{ap}}\right)$ & $2.03618 \mathrm{~m}^{2}$ \\
\hline 2 & Inside heat transfer area of absorber tube $\left(\mathrm{A}_{\mathrm{h}}\right)$ & $0.08819 \mathrm{~m}^{2}$ \\
\hline 3 & Absorber tube Length $\left(\mathrm{L}_{\mathrm{p}}\right)$ & $0.0236 \mathrm{~m}$ \\
\hline 4 & Absorber tube inner diameter $\left(\mathrm{D}_{\mathrm{i}}\right)$ & $0.0254 \mathrm{~m}$ \\
\hline 5 & Absorber tube outer diameter $\left(\mathrm{D}_{\mathrm{o}}\right)$ & $0.0710 \mathrm{~m}$ \\
\hline 6 & Outer diameter of glass cover $\left(\mathrm{D}_{\mathrm{co}}\right)$ & 0.90 \\
\hline 7 & Concentrator surface reflectivity & 0.85 \\
\hline 8 & Cover trasmissivity & $0.020 \mathrm{~m}$ \\
\hline 9 & Absorber tube absorptivity & $0.120 \times 10^{-2} \mathrm{~m}$ \\
\hline 10 & Perforated twisted tape's width $(\mathrm{w})$ & 58 \\
\hline 11 & Perforated twisted tape's thickness $(\mathrm{t})$ & $0.002 \mathrm{~m}, 0.003 \mathrm{~m}, 0.004 \mathrm{~m}$, \\
\hline 12 & No of perforated hole on each tape & $0.005 \mathrm{~m}$ \\
\hline 13 & Perforated hole diameters $\left(\mathrm{d}_{\mathrm{p}}\right)$ & $0.747 \%, 1.680 \%, 2.988 \%$, \\
& & $4.667 \%$ \\
\hline 14 & Porosity of tapes $($ Rp) & 4.5 \\
\hline 15 & & \\
\hline
\end{tabular}

A circulating pump pumps water to maintain water circulation continue into the receiver tube. To measure the water flow rate a water flow sensor is fitted at delivery of the pump. Two pressure transducers and two thermocouples, one of each at inlet and another of each at absorber tube's outlet are fitted to record the readings of pressures and temperatures at the corresponding places. Two LDR (a photo resistance) is fitted at the one end of the absorber tube to track the Sun during the experiment. During the experimental works, the solar intensity has by a Pyranometer (Solar Power Meter). The experimental works were carried out with and without inserting the PTT inside of the absorber tube. At the beginning of the experiments, first experiment was carried out for plain absorber 
Journal of Thermal Engineering, Research Article, Vol. 6, No. 5, pp. 802-815, October, 2020

and next experiments were carried out with placing PTT inside of the absorber tube in increasing order of porosity $(0.747 \%, 1.680 \%, 2.988 \%$ and $4.667 \%)$.

The experiments were performed during the month of December, 2017 in front of Mechanical Engineering Department of IIT(ISM) Dhanbad, India.

\section{DATA REDUCTION}

Absorber tube's inside flow area with PTT is calculated with the help of Equation 1 as follows,

$$
A_{f}=\frac{\pi D_{i}^{2}}{4}-w t
$$

The useful heat gain is determined with the help of Equation 2 as follows,

$$
Q_{u}=m c_{p}\left(T_{o}-T_{i}\right)
$$

Nusselt number is the non-dimensional parameter used for calculating the heat transfer between a flowing fluid and a solid body. It is determined using Equation 3 as follows,

$$
N u=\frac{h_{f} D_{h}}{k_{f}}
$$

The heat transfer coefficient is determined with the help of Equation 4 as follows,

$$
h_{f}=\frac{m c_{p}\left(T_{o}-T_{i}\right)}{A_{h}\left(T_{p}-T_{b}\right)}
$$

The Reynolds number (Re) is determined with taking the help of Equation 5 as follows,

$$
R e=\frac{\rho_{f} u_{f} D_{h}}{\mu_{f}}
$$

The equivalent hydraulic diameter $\left(D_{h}\right)$ at the entrance of the receiver tube having PTT insert is calculated with taking help of Equation 6 as follows,

$$
D_{h}=\frac{\pi D_{i}^{2}-4 w t}{\pi D_{i}+2(w+t)}
$$

The friction factor in term of pressure drop is calculated with the help of Equation 7 as follows,

$$
f=2 \frac{\Delta p D_{h}}{L_{p} \rho_{f} u_{f}^{2}}
$$

\section{UNCERTAINTY ANALYSIS}

The method invented by Kline and McClintock [24] has applied to evaluate the uncertainties in these experimental measurements. The uncertainty is calculated to be $1.699 \%$ for solar intensity, $\pm 6.024 \%$ for pressure drop, $\pm 6.052 \%$ for Reynolds number, $\pm 5.152 \%$ for heat transfer coefficient, $\pm 6.936 \%$ for the Nusselt number $(\mathrm{Nu})$ and $\pm 7.100 \%$ for friction factor (f) respectively. The instruments' accuracies and attachments' accuracies and have considered for uncertainty analysis have shown in Table 2. 
Table 2. Instruments' accuracy

\begin{tabular}{|c|c|c|}
\hline SI. No. & Instruments & Accuracy \\
\hline 1 & Water Flow Sensor & $\pm 10 \%$ \\
\hline 2 & Pyranometer & $\pm 0.499 \%$ or $\pm 10 \mathrm{~W} / \mathrm{m}^{2}$ \\
\hline 3 & Thermocouple & $\pm 0.4 \%$ \\
\hline 4 & Pressure Transducer & $\pm 0.25 \%$ \\
\hline
\end{tabular}

\section{RESULTS AND DISCUSSION}

Figure 3 shows the plot of solar intensity against time on different dates. In Figure 3, it is also most transparent that the values of solar intensity enhance with the faster rates since 9:0 $\mathrm{h}$ to till noon and at noon its value reaches to a peak. After noon, solar intensity decreases.

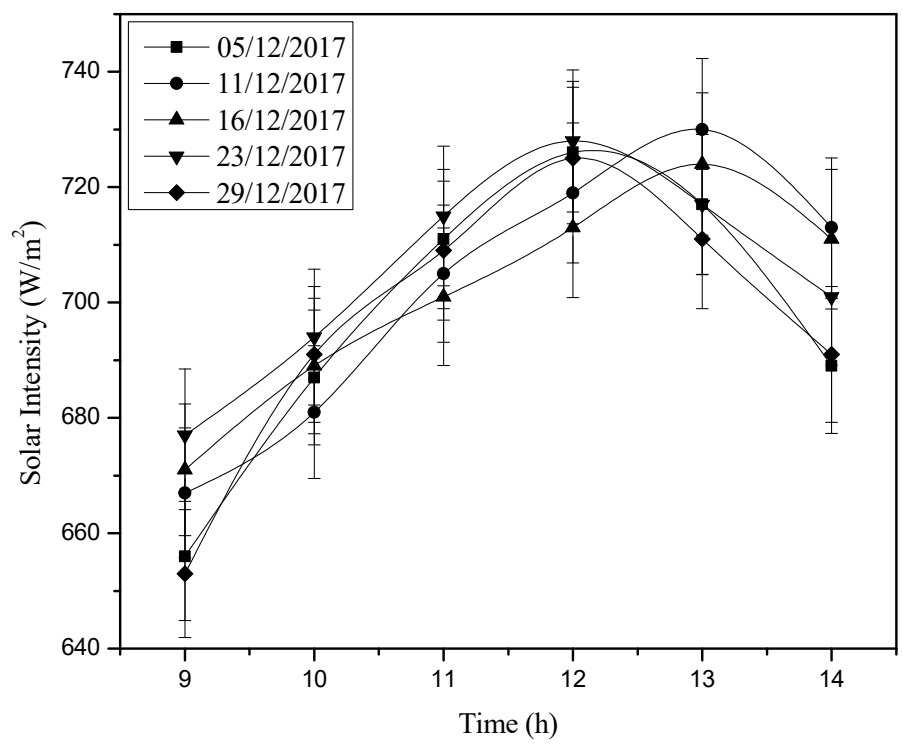

Figure 3. Solar intensity vs. time (h)

\section{INFLUENCE OF REYNOLDS NUMBER AND POROSITY OF PTT ON HEAT TRANSFER COEFFICIENT}

Figure 4 presents the change of heat transfer coefficient with respect to Reynolds number $(\mathrm{Re})$ for the absorber tube with and without PTT inserts. From Figure 4, it can be cleared that heat transfer coefficient always enhances with Reynolds number for the absorber tube with and without PTT inserts. Also enhances for the PTT fitted absorber tube with increasing porosity. Moreover, the additional water flow disturbance and secondary flow caused by holes on the tapes. This effect prolongs water flow duration and increases heat transfer rate from absorber tube's inner surface to circulating water. The average value of heat transfer coefficient obtained using perforated twisted tape with porosity $4.667 \%$, is $44.855 \%$ higher than that of the plain absorber tube. The heat transfer coefficients obtained using PTT with porosities $0.747 \%, 1.680 \%$ and $2.988 \%$ respectively, $27.812 \%, 34.247 \%$ and $39.093 \%$ higher than that obtained from a plain absorber tube result. 


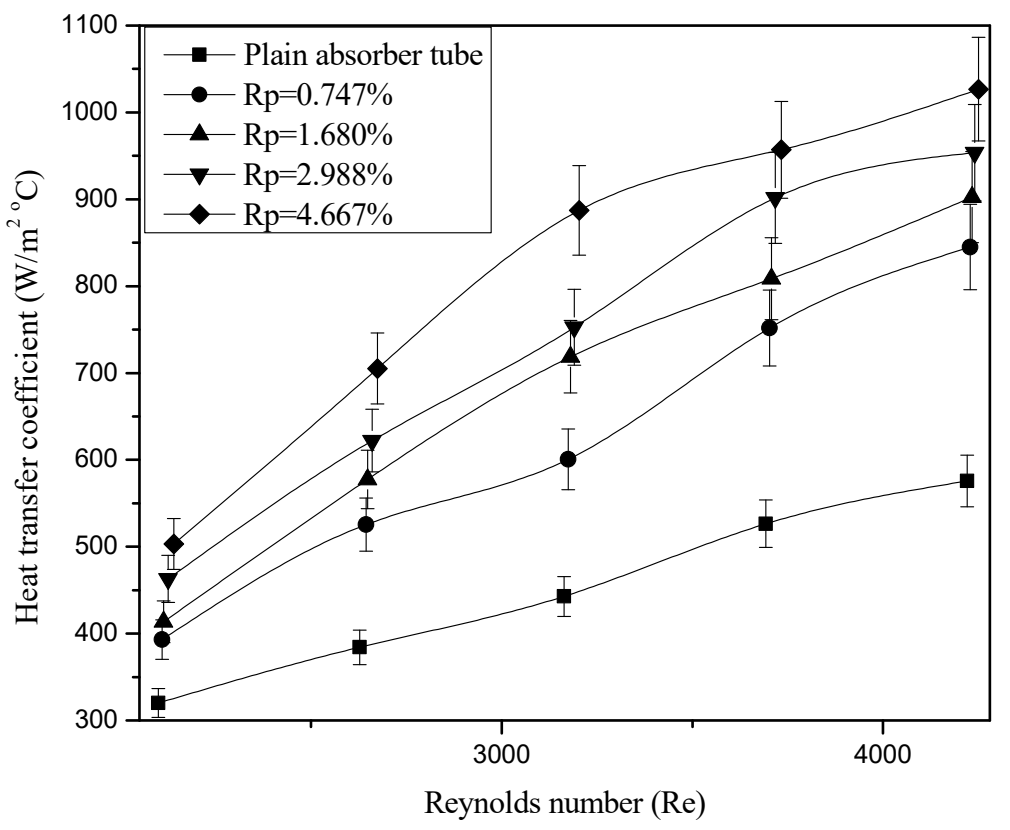

Figure 4. Variation of heat transfer coefficient against Reynolds number (Re) and porosity

\section{INFLUENCE OF REYNOLDS NUMBER AND POROSITY OF PTT ON NUSSELT NUMBER}

Figure 5 demonstrated the results of heat transfer in term of Nusselt number in the absorber tube equipped with PTT inserts at various porosities $(0.747 \%, 1.680 \%, 2.988 \%$ and $4.667 \%)$. The results show that Nusselt number enhances for the PTT inserts absorber tube with $\mathrm{Rp}=4.667 \%$. The high heat transfer rate at $\mathrm{Rp}=4.667 \%$ is attributed to a higher turbulent intensity and stronger swirl flow imparted to the flow. Thus, a stronger disturbance of a thermal boundary layer is created along the inner surface of the absorber tube, resulting the formation in a very thinner thermal boundary layer. The thinner thermal boundary layer is most favourable for heat transfer from inner surface to water. In addition to the above, the twisted tape and hole prolongs water flow duration which is main cause

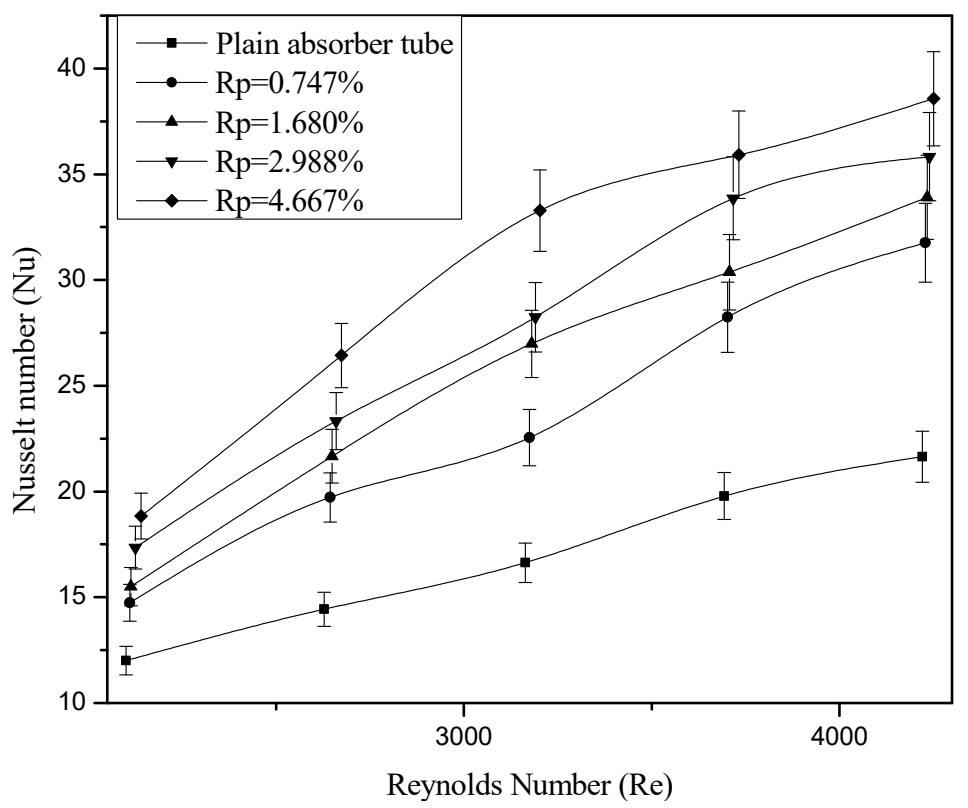

Figure 5. Variation of Nusselt number against Reynolds number and porosity 
of increase in overall heat transfer. The average value of Nusselt number $(\mathrm{Nu})$ obtained using PTT with porosity $4.667 \%$, is $44.783 \%$ higher than the same of a plain absorber tube. Nusselt numbers obtained using PTT with porosities $0.747 \%, 1.680 \%$ and $2.988 \%$ respectively, are $27.785 \%, 34.209 \%$ and $39.039 \%$ higher than that for a plain absorber tube.

\section{INFLUENCE OF REYNOLDS NUMBER AND POROSITY OF PTT ON PRESSURE DROP}

Figure 6 demonstrated the change of pressure drop with respect to Reynolds number and porosity of PTT. From this figure it is clear that pressure drop increases with Reynolds number and increasing porosity of tapes. Also, at $\mathrm{Rp}=4.667 \%$, pressure drop by PTT is much higher than those obtained by plain absorber tube and other PTT inserted absorber tube with porosities of $\mathrm{Rp}=2.988 \%, \mathrm{R}=1.680 \%$ and $\mathrm{Rp}=0.747 \%$ respectively. At same operating conditions, PTTs offer higher flow frictional resistances and drop pressures in the test section than plain absorber tube one. It is owing to the fact that the additional water flow disturbance and secondary flow caused by holes on the tapes. This effect increases the interaction between pressure and inertia forces, resulting in a pressure drop. Thus, the pressure drop increases with Reynolds number and increasing porosity of tapes. In the present investigation, the mean value of friction factor has found to be increased by $39.595 \%, 42.217 \%, 44.501 \%$ and $46.876 \%$ for the porosity of $\mathrm{Rp}=0.747 \%, \mathrm{Rp}=1.680 \%, \mathrm{Rp}=2.988 \%$ and $\mathrm{Rp}=4.667 \%$ respectively, under the similar flow conditions.

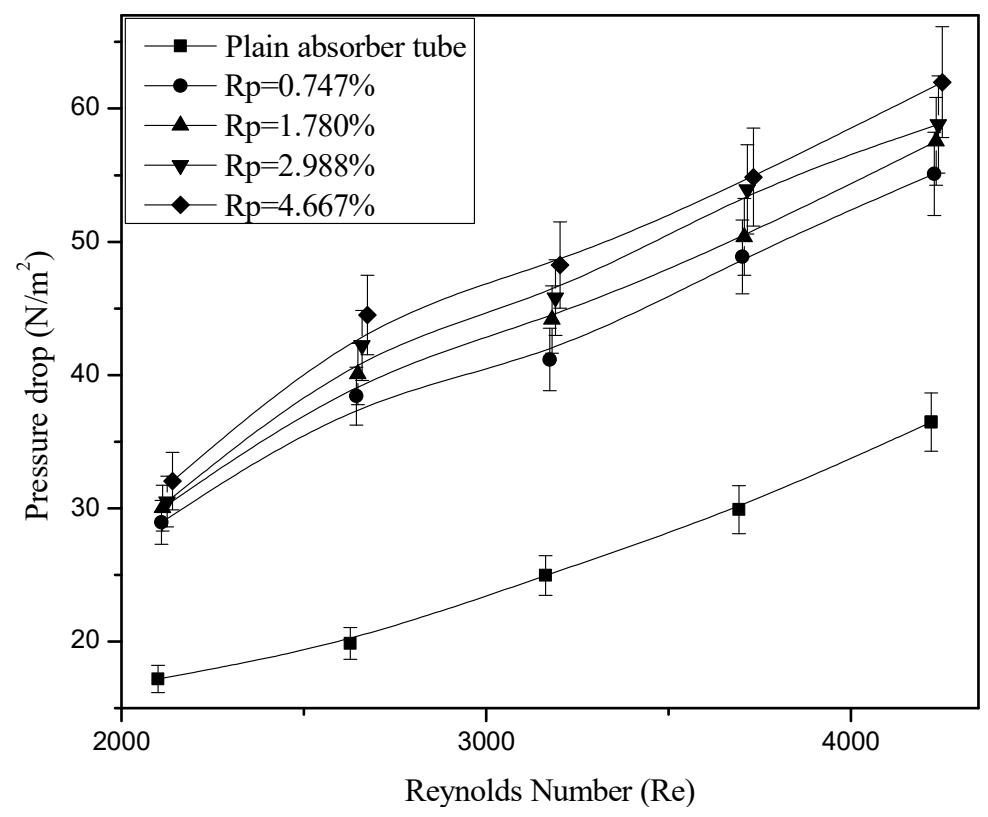

Figure 6. Variation of pressure drop $(\Delta \mathrm{p})$ vs. Reynolds number $(\mathrm{Re})$ and porosity

\section{INFLUENCE OF REYNOLDS NUMBER AND POROSITY OF PTT ON FRICTION FATOR}

Figure 7 demonstrated the change of friction factor with respect to Reynolds number (Re) and porosity of PTT. The value of friction factor increases with respect to Reynolds number and increasing porosity of tapes. At $\mathrm{Rp}=4.667 \%$, friction factor generated by PTT is much higher than those obtained by plain tube and PTT inserted absorber tube with porosities of $\mathrm{Rp}=2.988 \%, \mathrm{Rp}=1.680 \%$ and $\mathrm{Rp}=0.747 \%$ respectively. At same operating conditions, PTTs offer higher flow frictional resistance than plain absorber tube one. It is owing to the fact that the additional water flow disturbance caused by holes on tapes. This effect increases the interaction between pressure and inertia forces around the velocity boundary layer, resulting an increase in pressure drop and friction factor (f). In this investigation, the average value of friction factor (f) is observed to be increased by $44.960 \%$ for $\mathrm{Rp}=4.667 \%$, $42.371 \%$ for $\mathrm{Rp}=2.988 \%, 40.163 \%$ for $\mathrm{Rp}=1.680 \%$ and $37.476 \%$ for $\mathrm{Rp}=0.747 \%$ than that of plain absorber tube one. 


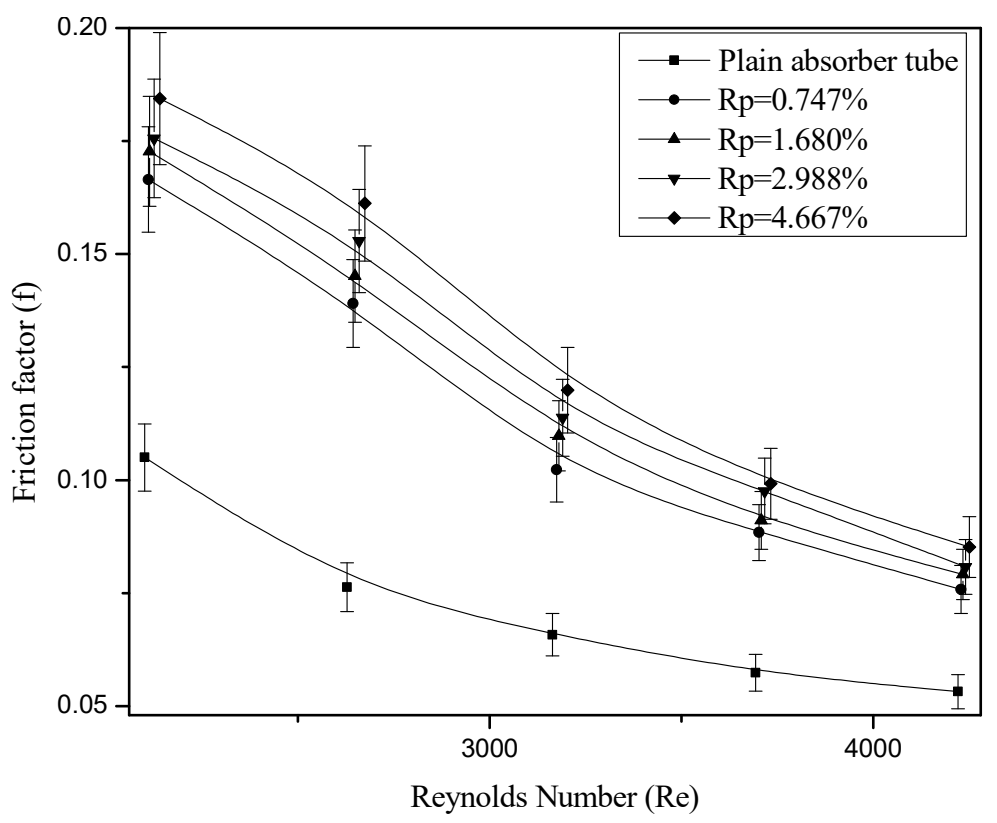

Figure 7. Variation of friction factor (f) against Reynolds number (Re) and porosity

\section{INFLUENCE OF MASS FLOW RATE AND POROSITY OF PTT ON INSTANTANEOUS EFFICIENCY}

Figure 8 presents the change of instantaneous efficiency $\left(\eta_{\mathrm{i}}\right)$ with water flow rate and porosity of tapes. For all the cases, instantaneous efficiency $\left(\eta_{i}\right)$ enhances mass flow rate. Instantaneous efficiency $\left(\eta_{i}\right)$ for

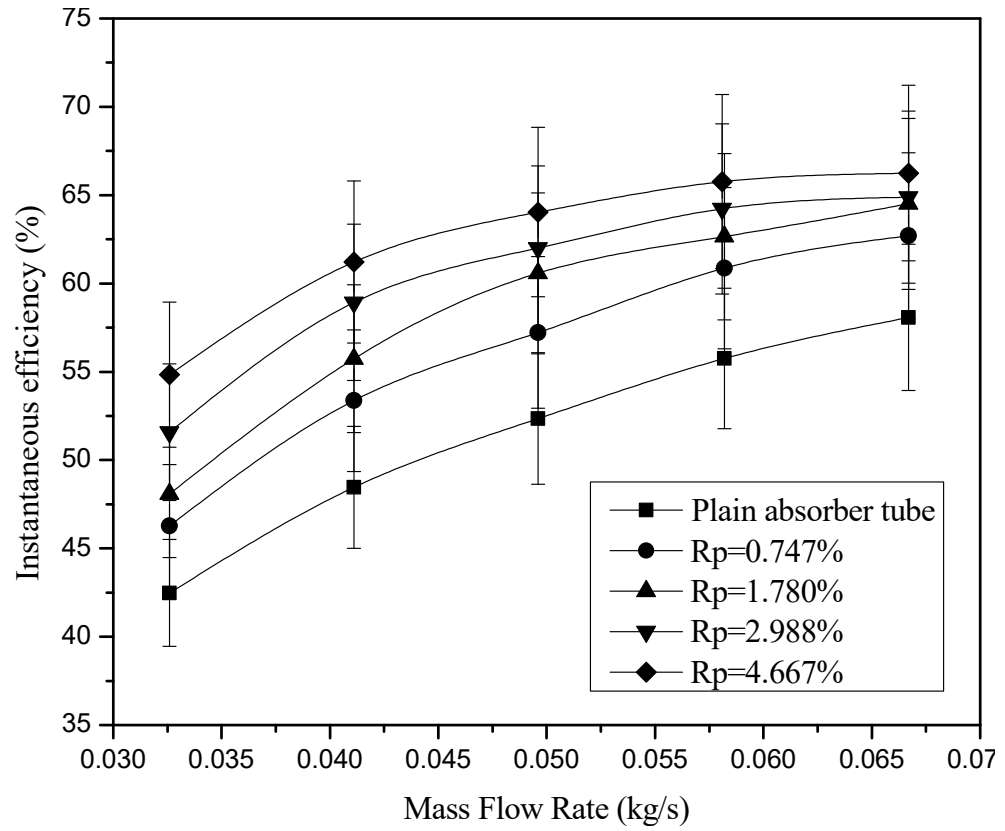

Figure 8. Variation of instantaneous efficiency $\left(\eta_{i}\right)$ against mass flow rate and porosity

PTT inserts absorber tube with $\mathrm{Rp}=4.667 \%$ is observed much better than the results calculated for others PTT inserts tube with $\mathrm{Rp}=2.988 \%, \mathrm{Rp}=1.680 \%, \mathrm{Rp}=0.747 \%$ and also than the result of a plain absorber tube. It is owing to the 
matter that heat transfer rate increases due to higher turbulent intensity and stronger swirl flow generated for the PTT inserts absorber tube with $\mathrm{Rp}=4.667 \%$. In addition to the above, the twisted tape and perforated hole prolongs water flow duration which is main cause of increase in overall heat transfer. The resultant effect increases the useful heat gain result of PCSWH. In this investigation, the mean value of instantaneous efficiency is found to be increased by $17.616 \%$ for PTT at $\mathrm{Rp}=4.667 \%, 14.751 \%$ for PTT at $\mathrm{Rp}=2.988 \%, 11.809 \%$ for PTT at $\mathrm{Rp}=1.680 \%, 8.305 \%$ for $\mathrm{PTT}$ at $\mathrm{Rp}=0.747 \%$ than the same result obtained for a plain absorber tube, under similar flow rate.

\section{INFLUENCE OF MASS FLOW RATE AND POROSITY OF PTT ON TEMPERATURE RISE PARAMETER}

Figure 9 presents the change of Temperature Rise Parameter (TRP) with respect to mass flow rate (m) and Rp of PTT. For all the cases, Temperature Rise Parameter (TRP) enhances with an increase in mass flow rate. Temperature Rise Parameter (TRP) for PTT inserts absorber tube with Rp $=4.667 \%$ is observed much better than the results calculated for others PTT inserts absorber tube with $\mathrm{Rp}=2.988 \%, \mathrm{Rp}=1.680 \%, \mathrm{Rp}=0.747 \%$ and also than the result of a plain absorber tube. It is owing to the matter that heat transfer rate increases due to higher turbulent intensity and stronger swirl flow generated by the PTT inside of the absorber tube with $\mathrm{Rp}=4.667 \%$. In addition to the above, the twisted tape and hole/pore prolongs water flow duration which is main reason of increase in overall heat transfer and rise in temperature. The resultant effect increases the value of useful heat gain. In this investigation, the mean value of TRP has found to be enhanced by $18.543 \%$ for PTT at Rp=4.667\%, $15.357 \%$ for PTT at $\mathrm{Rp}=2.988 \%, 11.971 \%$ for PTT at $\mathrm{Rp}=1.680 \%$ and $8.364 \%$ for PTT at $\mathrm{Rp}=0.747 \%$ than the result observed in case of a plain absorber tube, under similar operating condition.

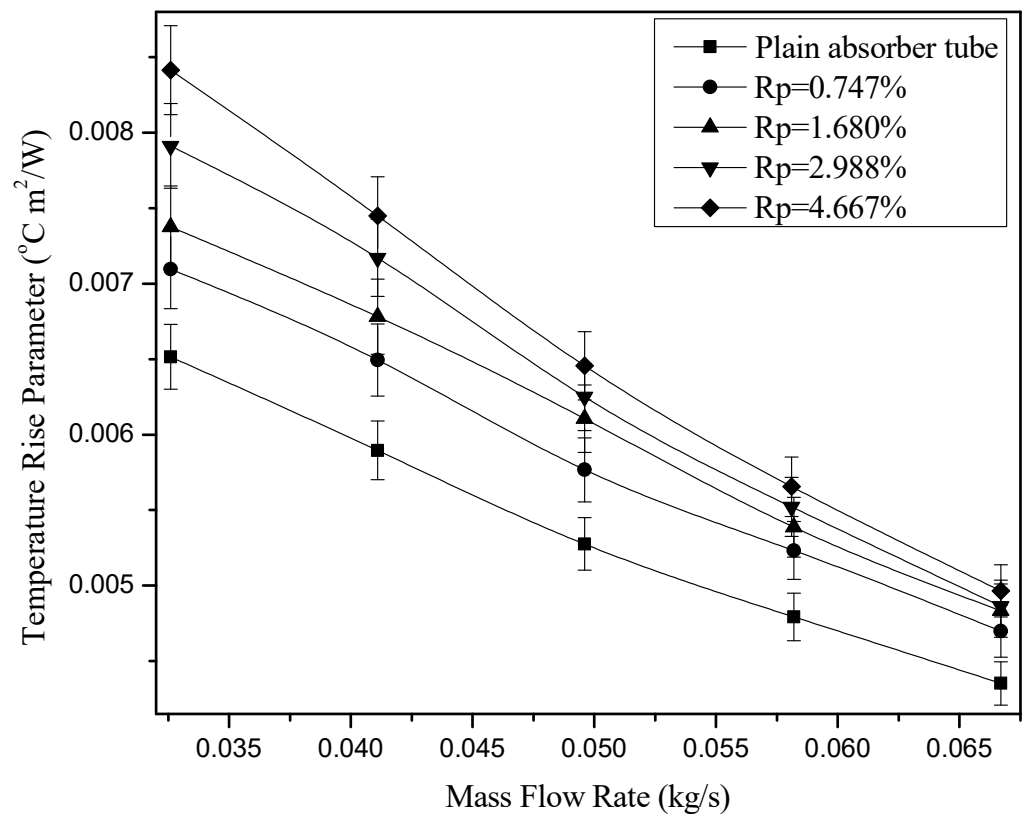

Figure 9. Variation of temperature rise parameter vs. mass flow rate and porosity

\section{INFLUENCE OF MASS FLOW RATE OF WATER AND POROSITY OF PTT ON WATER INLET AND OUTLET TEMPERATURES}

Figure 10 presents the variations of water inlet and outlet temperatures with variable water flow rate and $\mathrm{Rp}$ of PTT. For all the cases, the water outlet temperature reduces with an increase in water flow rate. Water outlet temperature for PTT inserted absorber tube with $\mathrm{Rp}=4.667 \%$ is observed much better than the results calculated for others PTT inserted absorber tube with $\mathrm{Rp}=2.988 \%, \mathrm{R}=1.680 \%, \mathrm{Rp}=0.747 \%$ and the result observed in case of a plain absorber tube. It is owing to the matter that heat transfer rate increases due to higher turbulent intensity and 
stronger swirl flow generated by the PTT inside of the absorber tube with $\mathrm{Rp}=4.667 \%$. In addition to the above, the twisted tape and perforated hole prolongs water flow duration which is main reason of increase in water outlet temperature.

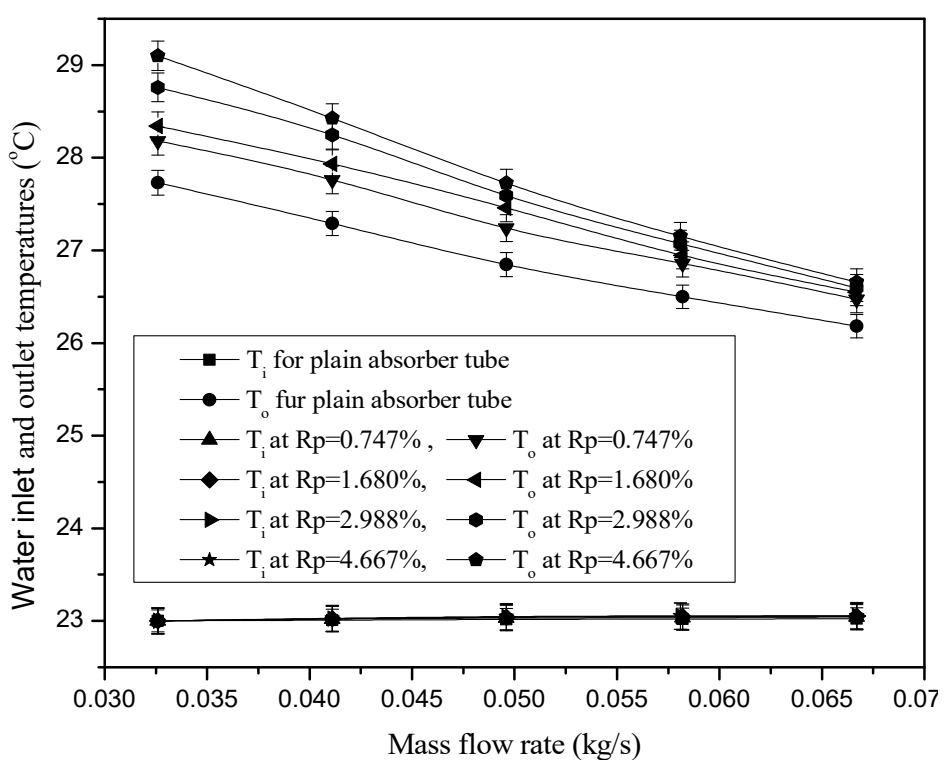

Figure 10. Variations of water inlet and water outlet temperatures with mass flow rate and porosity

\section{EMPIRIAL ORRELATION DEVELOPMENT FOR NUSSELT NUMBER}

Based on present experimental data $(4 \times 5=20$ runs), the correlations Nusselt number $(\mathrm{Nu})$ has been formulated as expressed in Equation 8 as follows,

$$
N u=0.0039 R e^{1.0005} \operatorname{Rp}^{0.1392} \mathrm{Pr}^{\mathbf{0 . 3 8 0}}
$$

From Equation 8 it is very transparent that $\mathrm{Re}, \mathrm{Rp}$ and $\mathrm{Pr}$, all directly influence the Nusselt number $(\mathrm{Nu})$. A correlation coefficient of 0.970 indicates the predicted result of Nusselt number holds very good agreement with experimental result of Nusselt number as shown in Figure 11. 
Journal of Thermal Engineering, Research Article, Vol. 6, No. 5, pp. 802-815, October, 2020

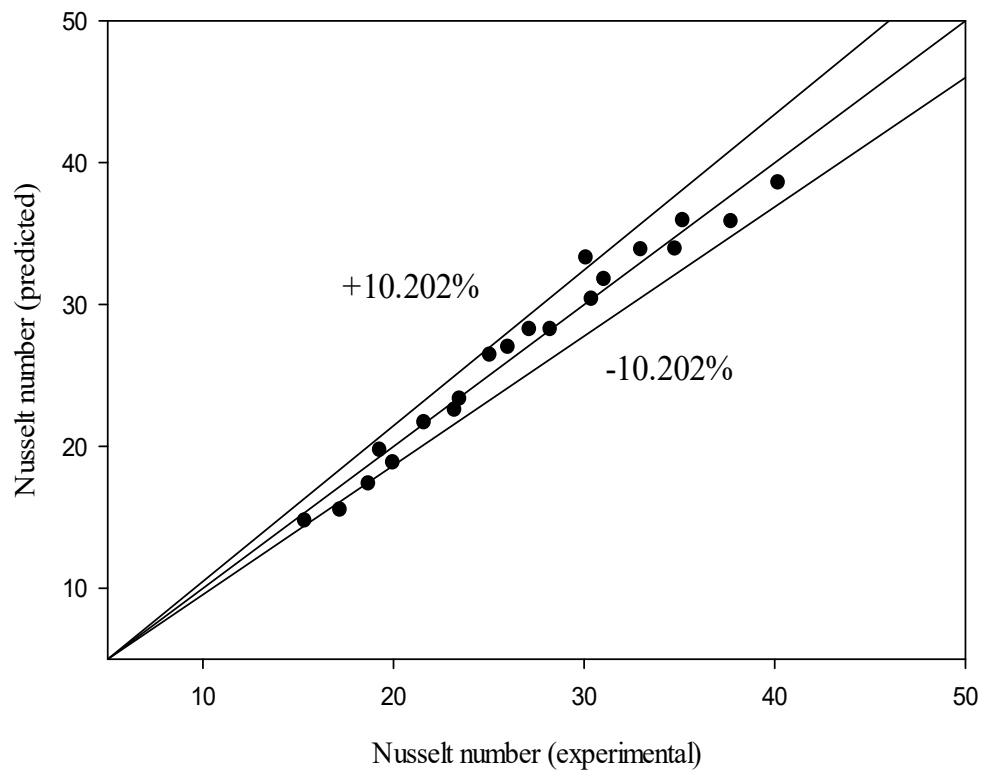

Figure 11. Parity plot of predicted and experimental values of Nusselt number

\section{EMPIRIAL ORELATIO DEVELOPMENT FOR FRICTION FATOR}

Based on present experimental data, the friction factor (f) correlated with Re and porosity (Rp) as expressed in Equation 9 as follows,

$$
f=918.9528 R e^{-1.1221} R p^{0.0740}
$$

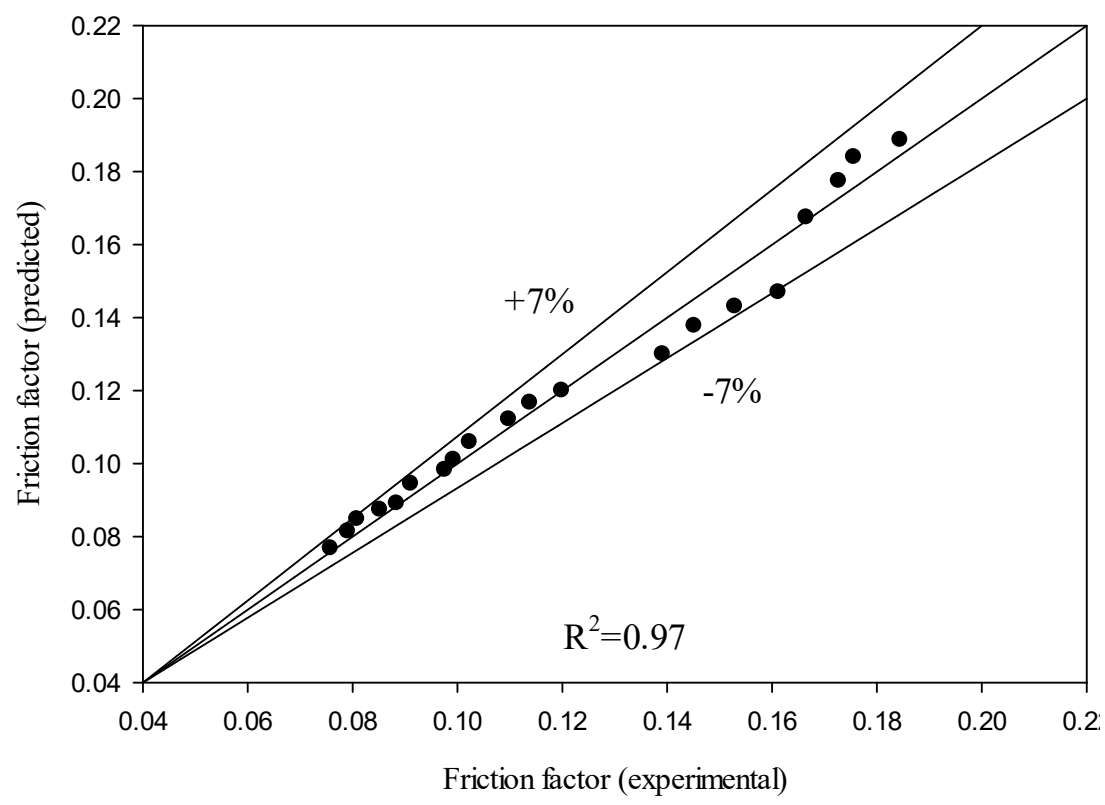

Figure 12. Parity plot of predicted and experimental values of friction factor 
From Equation 9 it is very transparent that Rp directly influences and Re inversely influences the friction factor (f) result. The correlation coefficient of 0.970 indicates the predicted result of friction factor holds very good agreement with experimental result of Nusselt number as shown in Figure 12.

\section{CONCLUSION}

The conclusions have been drawn from the above results and discussions as follows:

The Nusselt number, friction factor and heat transfer coefficient increase with increasing porosity of the tapes. The Nusselt number and heat transfer coefficient both enhances with Reynolds number (Re). Whereas, friction factor (f) reduces with increasing Reynolds number $(\mathrm{Re})$. As the frictional resistance decreases with an increase in Reynolds number (Re).

The instantaneous efficiency $\left(\eta_{i}\right)$ enhances with increasing mass flow rate. Whereas, water outlet temperature and TRP, both reduces with an increase in Reynolds number (Re). Instantaneous efficiency, water outlet temperature and temperature rise parameter, all are increases with increasing porosity of tapes.

To predict the enhancement in heat transfer and pressure drop considering the effect of PTT, correlations are developed for Nusselt number and friction factor. The predicted values of Nusselt number and friction factor are observed to be within $\pm 10.202 \%$ and $\pm 7.0 \%$ with experimental data.

\section{NOMENCLATURE}

$A_{a p} \quad$ Aperture of concentrator, $m^{2}$

$A_{h} \quad$ Absorber tube's inside surface area, $m^{2}$

$A_{f} \quad$ Absorber tube's flow area, $m^{2}$

$A_{p} \quad$ Total perforated holes area, $m^{2}$

$c_{p} \quad$ Specific heat, $\mathrm{J} / \mathrm{kg} \mathrm{K}$

$D_{i} \quad$ Absorber tube's inside diameter, $m$

$D_{0} \quad$ Absorber tube's outside diameter, $m$

$D_{h} \quad$ Hydraulic diameter, $m$

$D_{p} \quad$ Diameter of perforated holes, $m$

$f \quad$ Friction factor, nd

$h_{f} \quad$ Heat transfer coefficient, $\mathrm{W} / \mathrm{m}^{2} \mathrm{~K}$

$I_{b} \quad$ Intensity of solar radiation, $\mathrm{W} / \mathrm{m}^{2}$

$k_{f} \quad$ Thermal conductivity of water, $\mathrm{W} / \mathrm{m} \mathrm{K}$

$L_{p t t} \quad$ PTT length, $m$

$L_{p} \quad$ Absorber tube's length, $m$

$m \quad$ Mass flow rate, $\mathrm{kg} / \mathrm{s}$

$\mathrm{Nu} \quad$ Nusselt Number, nd

$P \quad$ PTT twist pitch, $m$

$Q \quad$ Useful heat gain, $\mathrm{W}$

Re Reynolds Number, nd

$R p \quad$ Porosity $\left(=\mathrm{A}_{\mathrm{p}} /\left(\mathrm{L}_{\mathrm{ptt}} \times \mathrm{w}\right)\right)$, nd

$u_{f} \quad$ Water velocity, $\mathrm{m} / \mathrm{s}$

$t \quad$ PTT thickness, $m$

$T_{i} \quad$ Inlet temperature, ${ }^{\circ} \mathrm{C}$

$T_{o} \quad$ Outlet temperature, ${ }^{\circ} \mathrm{C}$

$T_{p} \quad$ Surface temperature of absorber tube, ${ }^{\circ} \mathrm{C}$

$T_{b} \quad$ Bulk mean temperature, ${ }^{\circ} \mathrm{C}$

TRP Temperature rise parameter, $\mathrm{m}^{2}{ }^{\circ} \mathrm{C} / \mathrm{W}$

w Width of PTT, $m$ 


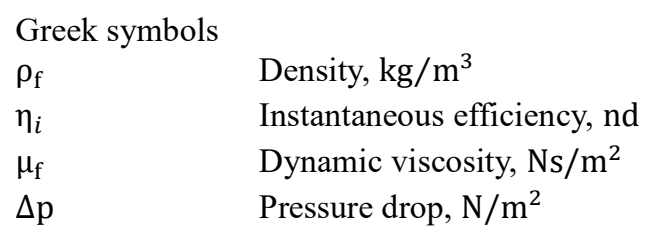

Subscripts

f Refers to fluid

$\begin{array}{ll}\text { Abbreviations } & \\ \text { PCSWH } & \text { Parabolic concentrating solar water heater } \\ \text { PTT } & \text { Perforated twisted tape } \\ \text { PTC } & \text { Parabolic trough concentrator }\end{array}$

\section{REFERENCES}

[1] Hong SW, Bergles AE. Augmentation of Laminal flow heat transfer in tubes by means of twisted-tape inserts. J Heat Transf 1976; 98: 251-256. https://doi.org/10.1115/1.3450527.

[2] Huang BJ, Wung TY, Nieh S. Thermal analysis of black liquid cylindrical parabolic collector. Sol Energy 1979; 22: 221-224. https://doi.org/10.1016/0038-092X(79)90136-1.

[3] Heiti RV, Thodos G. An experimental parabolic cylindrical concentrator: its construction and thermal performance. Sol Energy 1983; 30: 483-485. https://doi.org/10.1016/0038-092X(83)90120-2.

[4] Hamad FAW. The performance of a cylindrical parabolic solar concentrator. Energy Conver Managem 1988; 28: 251-256. https://doi.org/10.1016/0196-8904(88)90031-3.

[5] Mullick SC, Nanda SK. An Improved Technique for computing the heat loss factor of a tubular absorber. Sol Energy 1989; 42: 1-7. https://doi.org/10.1016/0038-092X(89)90124-2.

[6] Manglik RM, Bergles AE. Heat transfer and pressure drop correlations for twisted-tape inserts in isothermal tubes: Part I- Laminar Flows. J Heat Transf 1993;115: 881-889. https://doi.org/10.1115/1.2911383.

[7] Kothdiwala AF, Norton B, Eames PC. The effect of variation of angle of inclination on the performance of low-concentration-ratio compound parabolic concentrating solar collectors. Sol Energy 1995; 55: 301-309. https://doi.org/10.1016/0038-092X(95)00049-W.

[8] Agarwal SK., Raja Rao M. Heat transfer augmentation for the flow of a viscous liquid in circular tubes using twisted tape inserts. Int J Heat Mass transf 1996; 39: 3547-3557. https://doi.org/10.1016/0017-9310 (96)00039-7.

[9] Eskin N. Transient performance analysis of cylindrical parabolic concentrating collectors and comparison with experimental results. Energy Conver management 1999; 40: 175-191. https://doi.org/10.1016/S01968904(98)00035-1.

[10] Chang SW, Yang TL, Liou JS. Heat transfer and pressure drop in tube with broken twisted tape insert. Exp Therm Fluid Sci 2007; 32: 489-501. https://doi.org/10.1016/j.expthermflusci.2007.06.002.

[11] Arasu AV, Sornakumar T. Design, manufactured and testing of fiberglass reinforced parabola trough for parabolic trough solar collectors. Sol Energy 2007; 81: 1273-1279. https://doi.org/ 10.1016/j.solener.2007.01.005.

[12] Fadar AE, Mimet A, Perez-Garcia M. Modeling and performance study of a continuous adsorption refrigeration system driven by parabolic trough solar collector. Sol Energy 2009; 83, 850-861. https://doi.org/ 10.1016/j.solener.2008.12.003.

[13] Padilla RV, Demirkaya G, Goswami DY, Stefanakos E, Rahman MM. Heat transfer analysis of parabolic trough solar receiver. Appl Energy 2011; 88: 5097-5110. https://doi.org/ 10.1016/j.apenergy.2011.07.012.

[14] Kumaresan G, Sridhar R, Velraj R. Performance studies of a solar parabolic trough collector with a thermal energy storage system. Energy 2012; 47: 395-402. https://doi.org/10.1016/j.energy.2012.09.036.

[15] Jafar KS, Sivaraman B. Optimization of performance characteristics in the absorber with twisted tapes inserts of parabolic trough collector using response surface methodology. ARPN J Eng Appl Sci 2015; 10 (8): 3457 3464.

[16] Ghomrassi A, Mhiri H, Bournot P. Numerical study and optimization of parabolic trough solar collector receiver tube. J Sol Energy Eng 2015; 137: 0510031-05100310. https://doi.org/10.1115/1.4030849.

[17] Roy S, Asirvatham LG, Kunhappan D, Cephas E, Wongwises S. Heat transfer performance of silver/water nanofluid in a solar flat-plate collector. J Therm Eng 2015; 1(2): 104-112. https://doi.org/10.18186/jte.29475. 
Journal of Thermal Engineering, Research Article, Vol. 6, No. 5, pp. 802-815, October, 2020

[18] Bhakta, AK., Kumar, B. Singh, SN. Investigation on the Performance of a Cylindrical Parabolic Concentrating Solar Water Heater. Indian J Sci Technol 2016; 9: 1-7. https://doi.org/ 10.17485/ijst/2016/v9i48/105785.

[19] Hussein AK, Walunj A A, Kolsi L. Applications of nanotechnology to enhance the performance of the direct absorption solar collectors. 2016. J Therm Eng 2016; 2: 529-540. https://doi.org/10.18186/jte.46009.

[20] Soudani ME, Aiadi KE, Bechki D, Chihi S. Experimental and theoretical study of parabolic trough collector (PTC) with a flat glass cover in the region of Algerian Sahara (Ouargla). J Mech Sci Technol 2017; 31: 40034009. https://doi.org/10.1007/s12206-017-0747-3.

[21] Yildirim C, Ozdil NFT. Theoretical investigation of a solar air heater roughened by ribs and grooves. J Therm Eng 2018; 4(1): 1702-1712. https://doi.org/10.18186/journal-of-thermal-engineering.365713.

[22] Tokgoz N, Alic E, Kaska O, Aksoy MM. The numerical study of heat transfer enhancement using Al2O3water nanofluid in corrugated duct application. J Therm Eng 2018; 4(3): 1984-1997. https://doi.org/10.18186/journal-of-thermal-engineering.409655.

[23] Bhakta AK., Panday NK, Singh SN. Performance study of cylindrical parabolic concentrating solar water heater with nail type twisted tape inserts in the absorber tube. Energies 2018; 11 (1): 1-15. https://doi.org/10.3390/en11010204.

[24] Kline SJ, McKlintock FA. Describing uncertainties in single-sample experiments. Mech Eng 1953; 75: 3-8. 